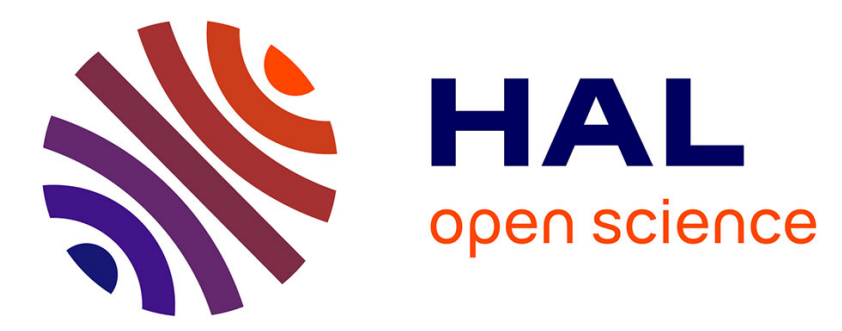

\title{
Computational material design of filled rubbers using multi-objective design exploration
}

\author{
Masataka Koishi, Naoya Kowatari, Bruno Figliuzzi, Matthieu Faessel, \\ François Willot, Dominique Jeulin
}

\section{- To cite this version:}

Masataka Koishi, Naoya Kowatari, Bruno Figliuzzi, Matthieu Faessel, François Willot, et al.. Computational material design of filled rubbers using multi-objective design exploration. 10th European Conference on Constitutive Models for Rubbers (ECCMR), Aug 2017, Munich, Germany. hal-01609886

HAL Id: hal-01609886

https://hal-mines-paristech.archives-ouvertes.fr/hal-01609886

Submitted on 4 Oct 2017

HAL is a multi-disciplinary open access archive for the deposit and dissemination of scientific research documents, whether they are published or not. The documents may come from teaching and research institutions in France or abroad, or from public or private research centers.
L'archive ouverte pluridisciplinaire HAL, est destinée au dépôt et à la diffusion de documents scientifiques de niveau recherche, publiés ou non, émanant des établissements d'enseignement et de recherche français ou étrangers, des laboratoires publics ou privés. 


\title{
Computational material design of filled rubbers using multi-objective design exploration
}

\author{
M. Koishi \& N. Kowatari \\ The Yokohama Rubber Co.,Ltd., Hiratsuka, Japan \\ B. Figliuzzi, M. Faessel, F. Willot \& D. Jeulin \\ MINES ParisTech, PSL Research University, CMM, Fontainebleau, France
}

\begin{abstract}
The rubber materials of tires contain nano-fillers i.e. carbon black and silica for the improvement of tire performances. The mechanical properties of filled rubber depend on the morphology of fillers. In this work multi-objective design exploration (MODE) is applied to material design of filled rubbers to get the information between mechanical properties and morphological design variables. A multi-scale random model based on a Poisson point process is used to generate a simulation model of filled rubber, and FFT (fast Fourier transform) based scheme is applied to solve large-scale dynamic viscoelastic simulation. To get big data including Pareto solution for data mining, multi-objective genetic algorithm are conducted on TSUBAME, supercomputer at Tokyo Institute of Technology. Data mining is employed to highlight properties-sensitive features in the microstructure. First, the volume fraction of bound rubber plays a major role in the material design of filled rubbers. Second, the radius of aggregates contributes to mechanical properties of filled rubbers.
\end{abstract}

\section{INTRODUCTION}

The rubber materials of tires contain nano-fillers i.e. carbon black and silica for the improvement of tire performances e.g. rolling resistance, wear and so on. The mechanical properties of filled rubber depend on the morphology of fillers. It is said that uniformly dispersed fillers are good to reduce loss tangent, however, guideline of material design to improve loss tangent, modulus and strength at the same time is not clear.

For clarification of the mechanism and origin of mechanical properties of filled rubbers, numerical simulation of filled rubbers has been conducted in the past few decades. Recently, large-scale simulation using the model generated by 3D-TEM (transmission electron microtomography) was conducted by Akutagawa et al. (2008) and Kadowaki et al. (2016) to compute effective material properties. Two-dimensional pattern reverse Monte Carlo analysis was performed to make structural model from the data obtained by time-resolved twodimensional ultra-small angle x-ray scattering (Hagita et al. 2007 \& Hagita et al. 2008). And to compute effective shear modulus, the complex multi-scale microstructure of filled rubber was generated numerically from a morphological model that was identified from statistical moments out of transmission electron microscopy images (Jean et al. 2011, for a simpler version).

The information on effective material properties and morphological design variables is helpful for the material design of filled rubbers. So, the objective of this work is to get the information using multiobjective design exploration (MODE). MODE has been already applied to tire design (Koishi et al.
2006 \& Koishi et al. 2014). MODE consists of numerical simulation, multi-objective genetic algorithm and data mining technique, and is a methodology to discover an evolutional idea for making technical innovation. However, to apply MODE to material design, especially morphological design of filled rubbers, there are two big issues i.e. simulation models in which morphology of fillers can be changed parametrically and large-scale viscoelastic simulation. In this study, the issues were solved using multi-scale random model based on Poisson point process and complex FFT (fast Fourier transform) based scheme proposed by Figliuzzi et al. (2016). In addition, MODE for the morphological design of filled rubbers was conducted on TSUBAME, supercomputer at Global Scientific Information and Computing Center in Tokyo Institute of Technology.

\section{SIMULATION MODELS AND LARGE-SCALE DYNAMIC VISCO-ELASTIC SIMULATION}

\subsection{Morphology of filled rubbers and their feature value}

This work concerns a rubber material reinforced by carbon black and silica particles as fillers, which are embedded in a matrix of rubber and can be geometrically well-approximated by spheres. A key feature of the material is that the rubber matrix is constituted of two distinct polymers: an exclusion polymer, which cannot contain any filler, and its complementary polymer, which can contain fillers. Fillers tend to agglomerate together within the rubber matrix. To analyze the rubbers microstructure, we dispose of a set of 50 TEM micrographs of size 1024 by 1024 pixels 


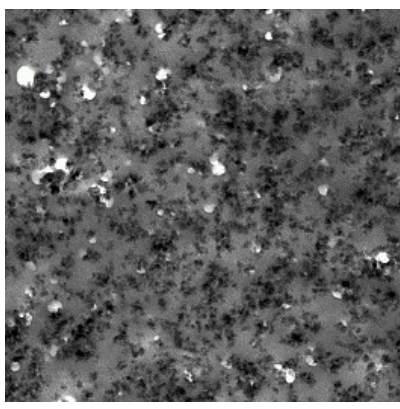

(a)

(b)

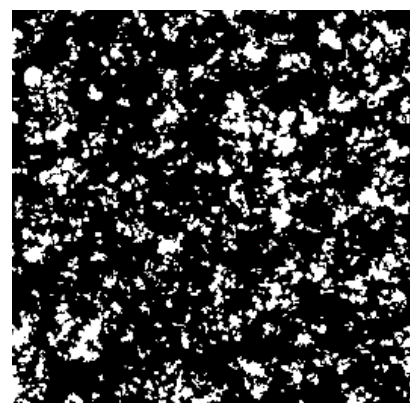

Figure 1. (a) Original TEM image of silica filled rubber, (b) segmented binary image showing the filler in white.

with resolution $2.13 \mathrm{~nm}$ per pixel. The slices of material probed by the microscope have a thickness around $40 \mathrm{~nm}$. The first task is to segment these images, in order to identify the spatial distribution of the fillers as shown in Figure 1.

An efficient way to keep track of the information embedded in the segmented images is to rely on a morphological characterization of the material. In this work, the covariance and the granulometry of fillers are used as feature value of morphology. The covariance and the cumulative granulometry curve of silica fillers are shown in Figure 2. Using the covariance and the granulometry curves, we can select parameters for the identification of multi-scale random models as explained in the next section. This is important way to merge the information between real material and simulation model at a material design stage.

\subsection{Multi-scale random model}

A multi-scale random model is used to describe the microstructure (Figliuzzi et al. 2016) as shown in Figure 3 . The first scale corresponds to the aggregates, while the second one describes more specifi-

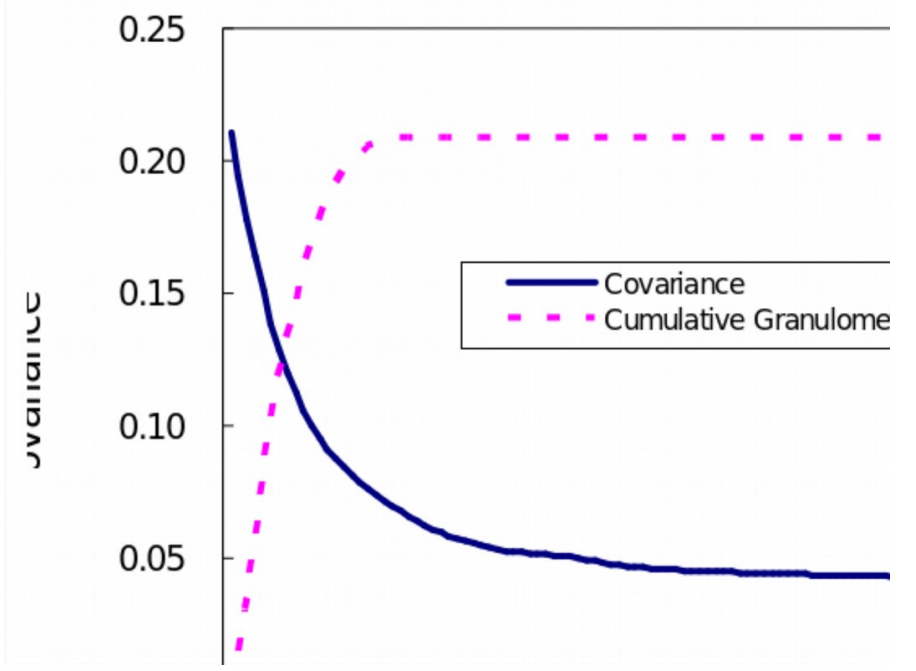

Figure 2. Covariance (solid line) and cumulative granulometry (broken line) computed from TEM image shown in Figure 1. cally the single particles inside the aggregates. In addition, several alternatives can be considered to locate the aggregates outside of the exclusion polymer. Bound rubber in Figure 3 is the interface layer between polymer and filler. Morphological parameters of a multi-scale random model are followings;

- Poisson point intensity and volume fraction of exclusion polymer,

- Poisson point intensity and radius of aggregate,

- Poisson point intensity or volume fraction and radius of filler,

- Overlapping distance of fillers,

- Thickness of bound rubber.

These parameters can be used as design variables for parametric study, optimization and MODE. For example, cross sections of six 3D simulation models generated by multi-scale random modeling are shown in Figure 4. These models are generated with different Poisson point intensity and radius of aggre-

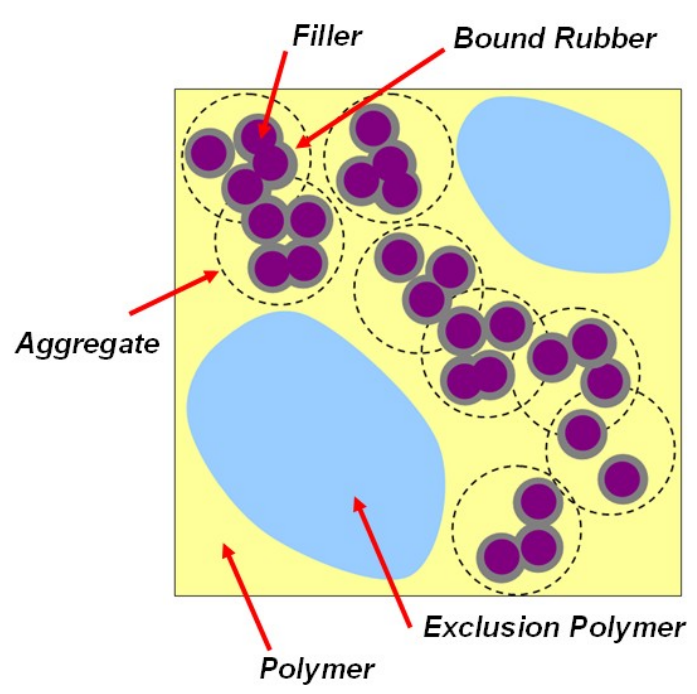

(a)

1st Scale

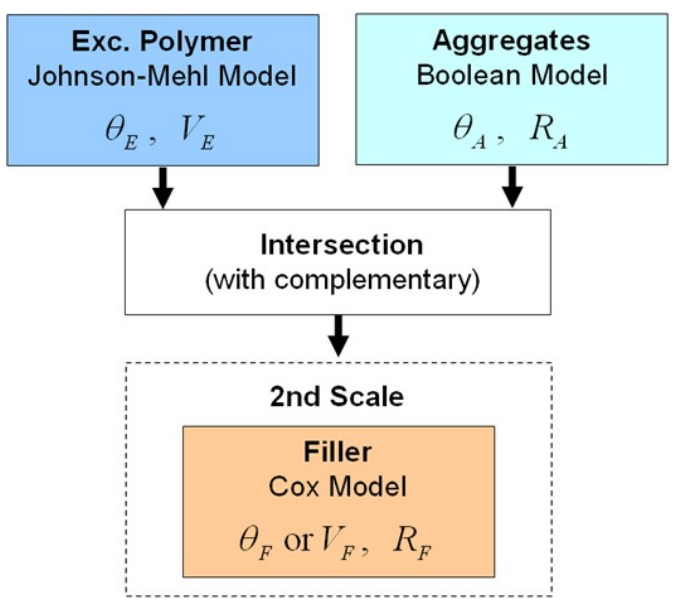

(b)

Figure 3. (a) Schematic figure of filled rubber constituted of two distinct polymers and (b) procedure of a multi-scale random model. 


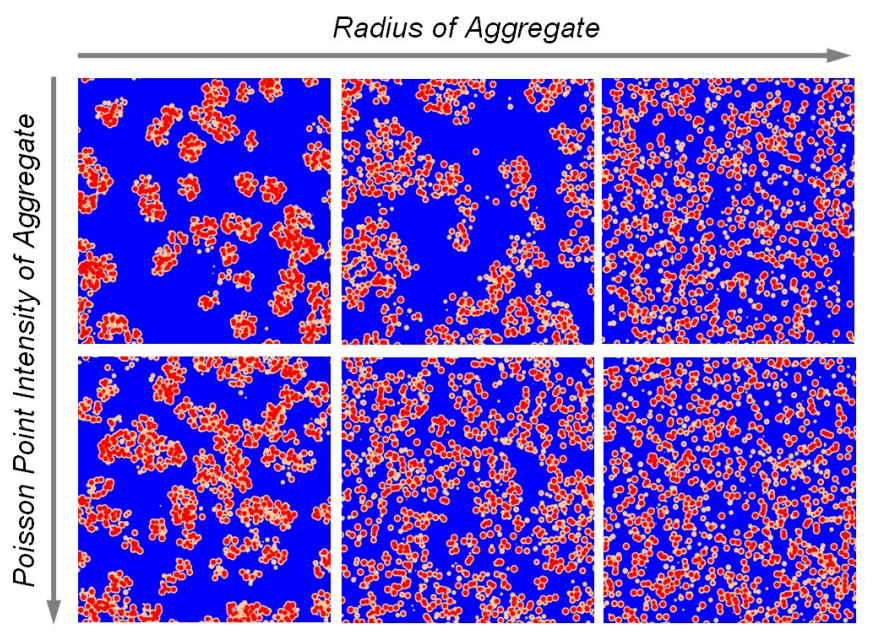

Figure 4. Cross section of six 3D simulation models generated with different Poisson point intensity and radius of aggregate, domain size: $1,000 \mathrm{~nm} \times 1,000 \mathrm{~nm} \times 1,000 \mathrm{~nm}$, the volume fraction of filler: $15 \%$, the radius of filler: $10 \mathrm{~nm}$, the thickness of bound rubber: $5 \mathrm{~nm}$.

gate as design parameters, however, the volume fraction and radius of filler remain constant.

\subsection{Computation of the effective dynamic visco- elastic properties using FFT-based scheme}

According to our research, RVE (representative volume element) size of multi-scale random model should be 20 times larger than the radius of filler. And for sufficient resolution of bound rubber, the element size of the bound rubber should be smaller than its thickness. Moreover more than thousand computations should be done to get a Pareto solution using multi-objective genetic algorithm. Therefore, a fast simulation scheme is needed for large-scale dynamic viscoelastic problems. Though the homogenization procedure based on FEM for dynamic viscoelasticity is proposed by Koishi et al. (1997), a

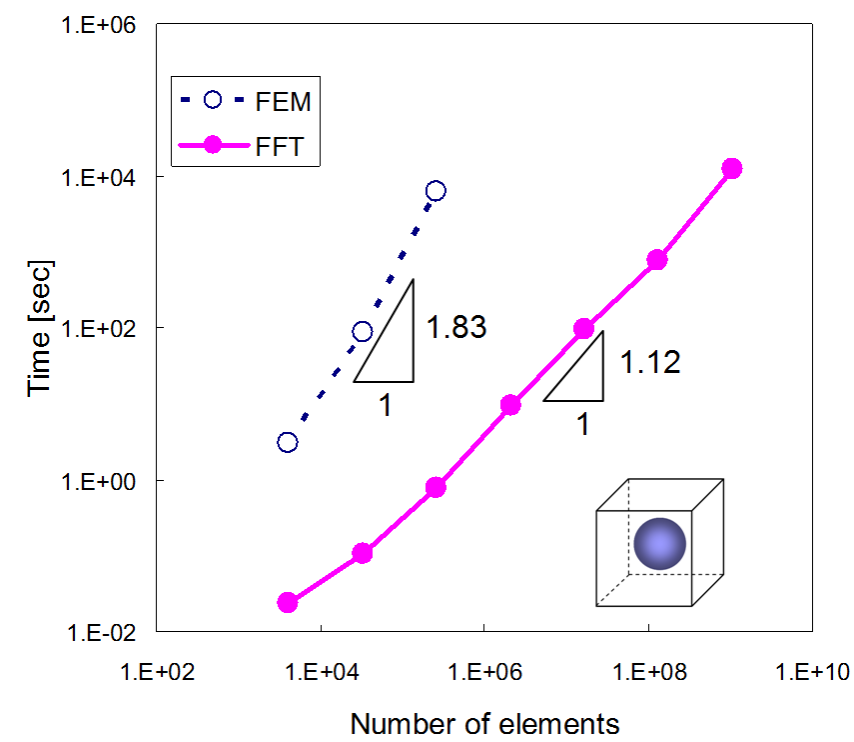

Figure 5. Computation time of the FFT-based scheme and FEM against the number of elements.

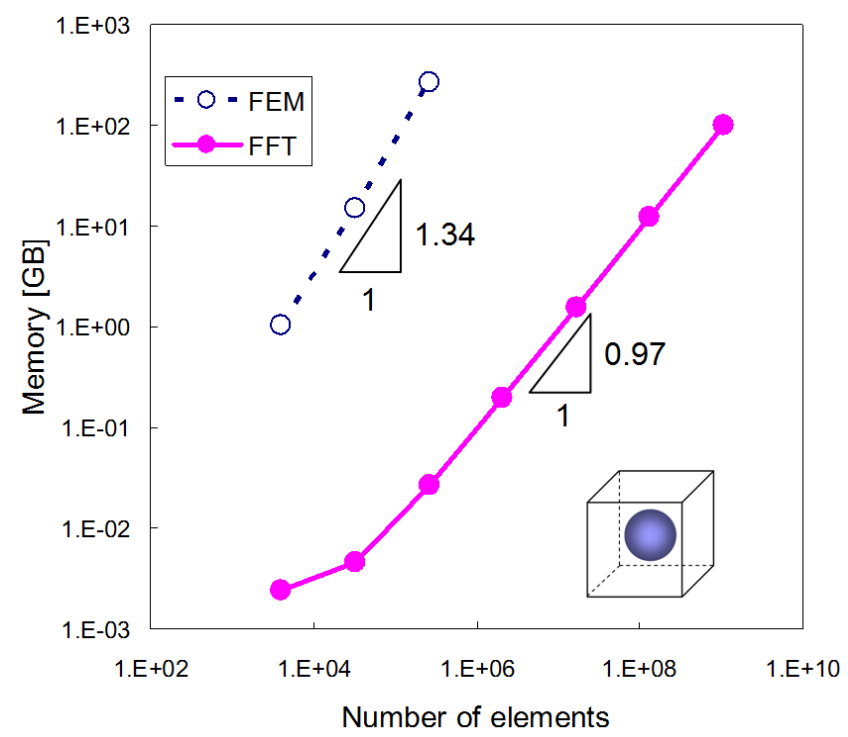

Figure 6. Required memory size of the FFT-based scheme and FEM against the number of elements.

FFT-based scheme (Figliuzzi et al. 2016 \& Willot 2015) is used in this study.

Here, we demonstrate the efficiency of FFT-based scheme as a solver of large-scale problems. A single spherical filler embedded in rubber matrix shown in Figure 5 is considered for a benchmark test. Simulation models are discretized in uniform voxel mesh. The largest model consists of over 1 billion elements (1024x1024x1024 elements). Figure 5 and Figure 6 show computation time and required memory of the FFT-based scheme against the number of elements, respectively. Those of FEM are also shown in the same figures. Both of FFT-based scheme and FEM were run on 8 CPUs. The computational time and required memory size of the FFT-based scheme are almost proportional to the number of elements. The figures show that as the number of elements increases, the FFT-based scheme is much faster than FEM.

\section{MULTI-OBJECTIVE DESIGN EXPLORATION FOR MORPHOLOGICAL DESIGN OF FILLED RUBBERS}

\subsection{Multi-objective design exploration (MODE)}

The decision making in the real world depends on multiple criteria. Multiple criteria decision making is indispensable even in the design process of rubber materials of tires. So the material design of rubber is so-called multi-objective design optimization. The multi-objective design optimization is to find design variables which minimize or maximize each objective function i.e. mechanical properties of filled rubbers. Since some of objective functions have tradeoff, a set of optimal solutions called Pareto solution is found out in the multi-objective optimization. We can obtain design information by clarifying the relationship between objective functions and design 


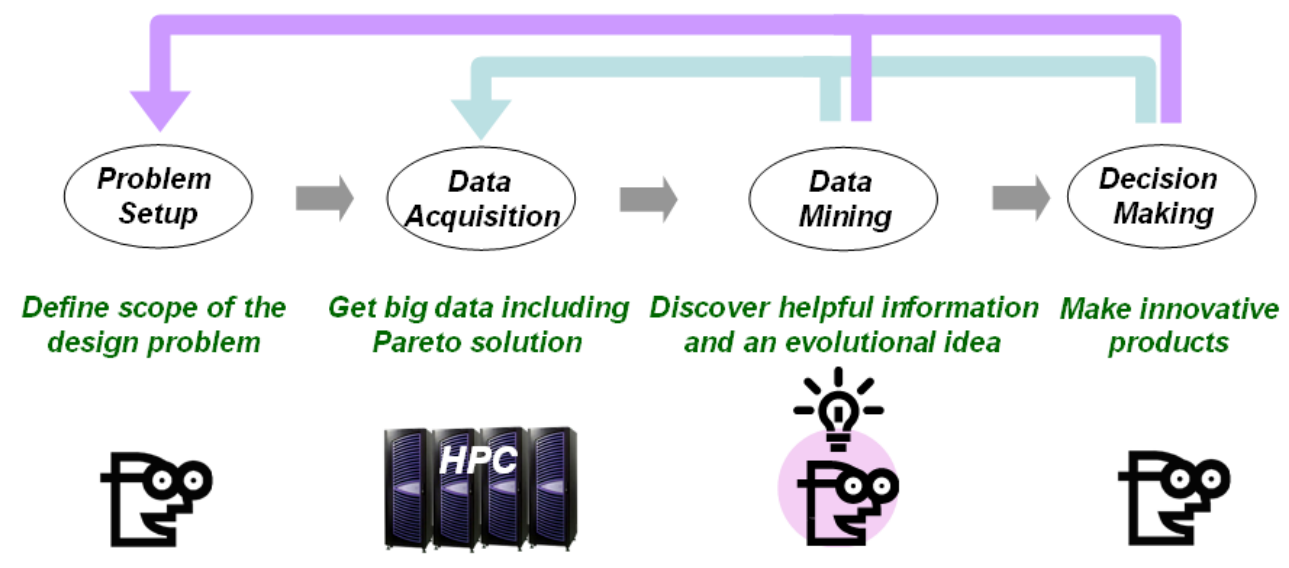

Figure 6. Procedure of multi-objective design exploration (MODE) to discover helpful information and an evolutional idea for making new productions. HPC stands for high performance computing.

variables in design space including Pareto solutions. The information and the evolutional idea inspired by the information are helpful for the multi-criteria decision making at material design stage.

MODE is a methodology to get helpful information between objective functions and design parameters using multi-objective optimization and data mining. From the information, we can find out an evolutional idea for making new productions. Figure 7 shows procedure of MODE. Here the procedure of MODE consists of FFT-based scheme to simulate properties of filled rubber generated by multi-scale random model, evolutional computation e.g. multi-

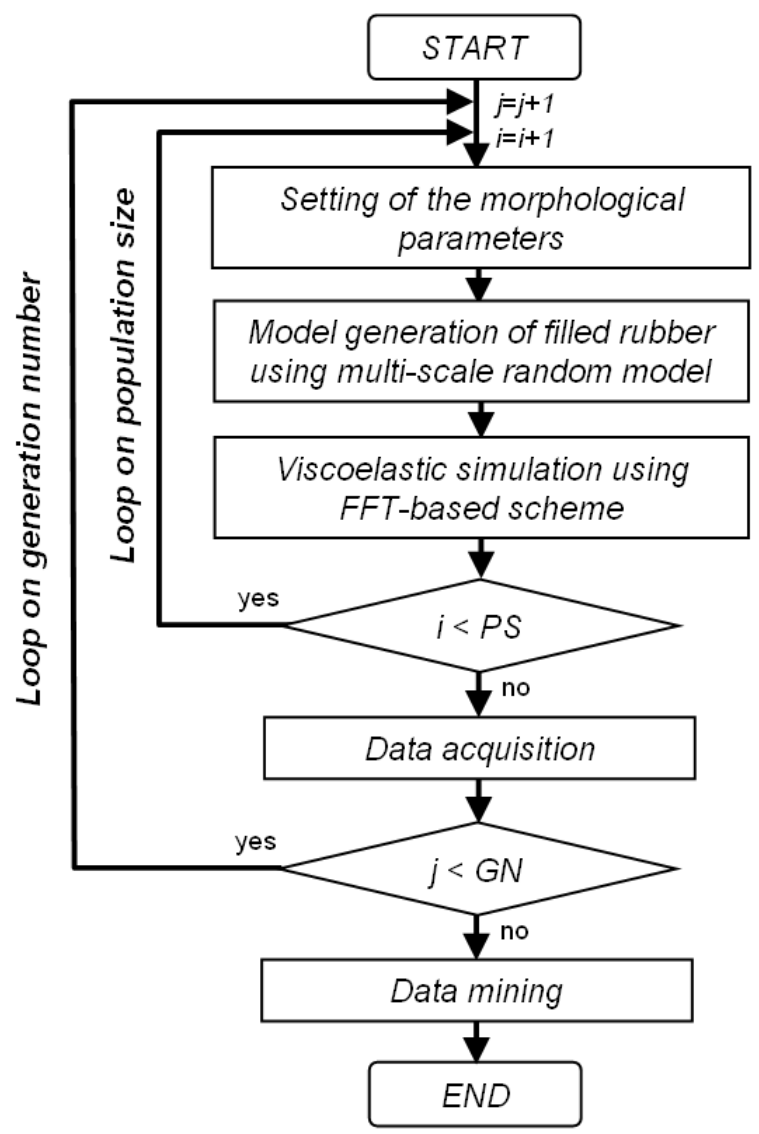

Figure 7. MODE for morphological design of filled rubbers. PS and GN stand for population size and generation number in multi-objective genetic algorithm. objective genetic algorithm to get desirable solutions including Pareto solution, and data mining using self-organizing map (SOM) to find out morphological design information of filled rubbers as shown in Figure 7. Since the viscoelastic simulation of each individual can be conducted independently, parallel computing is effective in this study.

\subsection{Problem set-up}

The simulation model of the filled rubber which consists of three domain i.e. polymer, filler and bound rubber is considered here. Modulus of polymer, filler and bound rubber are $2 \mathrm{MPa}, 2000 \mathrm{MPa}$ and $20 \mathrm{MPa}$, respectively. And loss tangent of polymer, filler and bound rubber are $0.05,0.0$ and 0.1 , respectively. The radius of filler is $10 \mathrm{~nm}$ and the size of RVE is $500 \mathrm{~nm}^{3}$. Figure 8 shows a simulation model which consists of 134 million elements (512x512x512 elements) to resolve the bound rubber of the thickness of $5 \mathrm{~nm}$.

The design variables are the following parameters that can change the morphology of filler;

- Poisson point intensity of aggregate,

- Radius of aggregate,

- Volume fraction of filler,

- Overlapping distance of fillers.
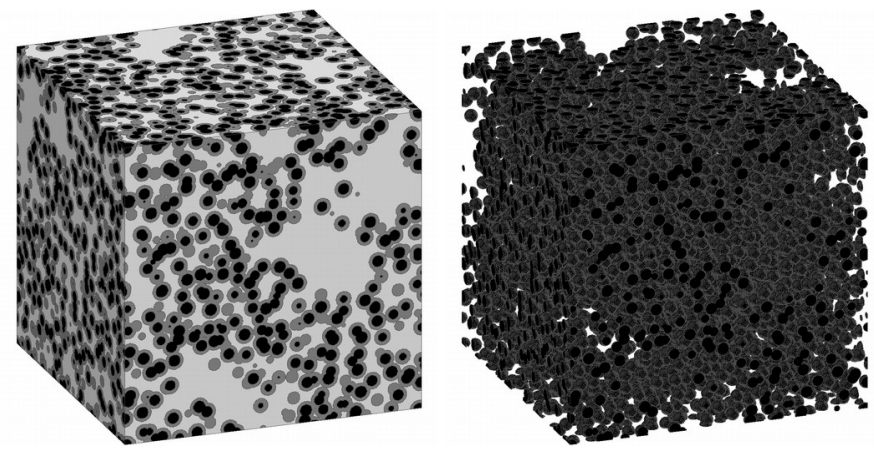

Figure 8. (a) 3D simulation model of filled rubber generated by multi-scale random model and (b) fillers embedded in the model. The number of elements is 134 million (512x512x512). 
The objective functions are following;

- Effective loss tangent (to be minimized),

- Effective modulus (to be maximized),

- Average Mises stress in polymer domain (to be minimized),

- Standard deviation of Mises stress in polymer domain (to be minimized).

The last two objective functions are as indicators of resistance to wear. A multi-objective genetic algorithm, NSGA-II (Deb et al. 2000) is used to get data set including Pareto solution. The population size is 100 , and the generation number is 40 . Therefore, the computation of 4,000 large-scale models which consist of 134 million elements is carried out in this study.

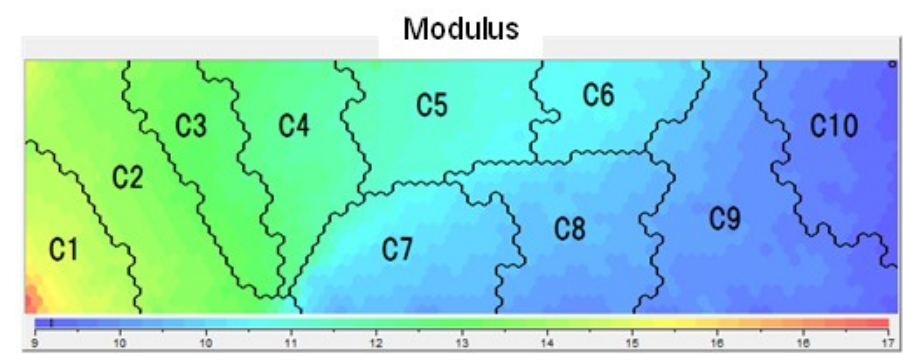

Average of Mises stress in polymer domain

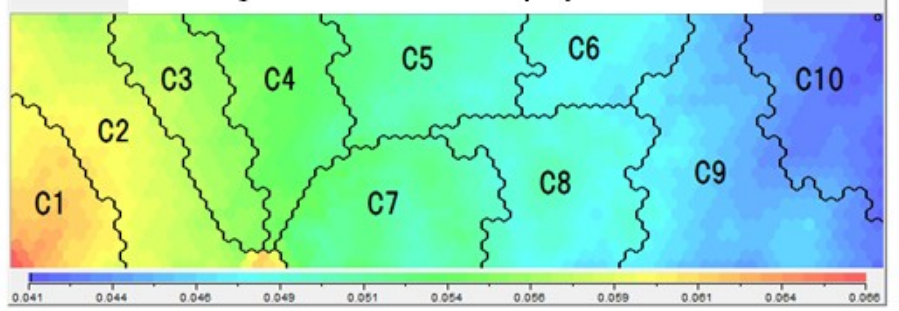

Poisson point intensity of aggregate

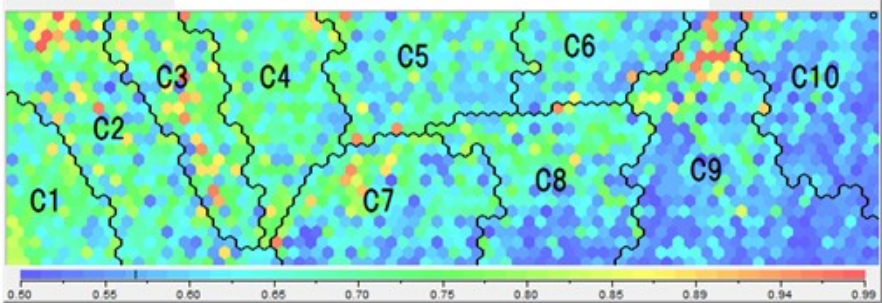

Overlapping distance of fillers

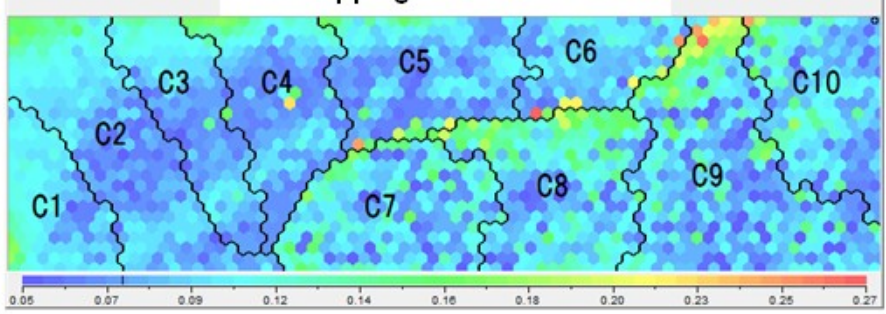

Volume fraction of polymer
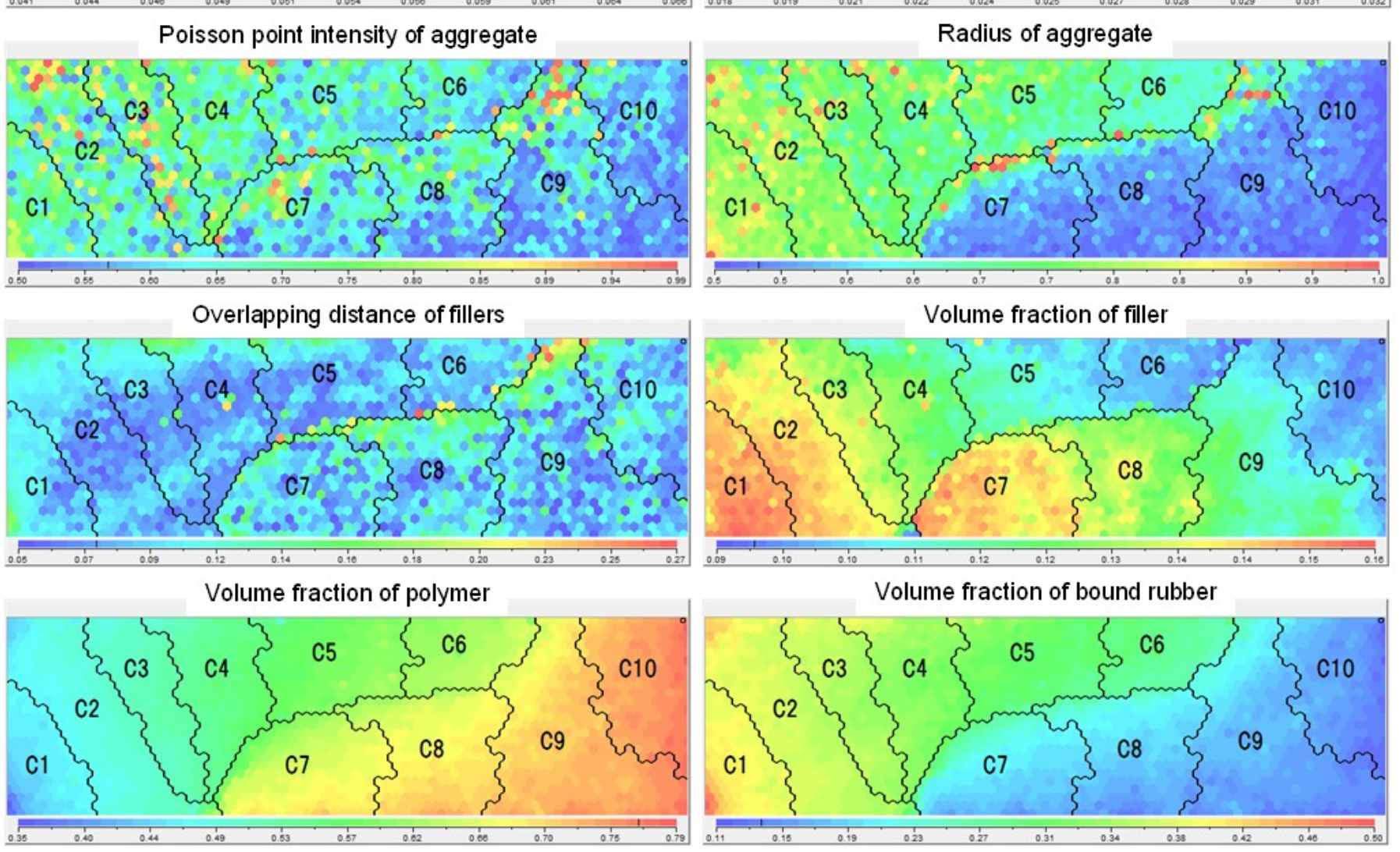

\subsection{Data mining using SOM (self-organizing map)}

A sophisticated visualization technique is required to show high-dimensional objective functions and design parameters simultaneously. To visualize highdimensional data, self-organizing map (SOM) proposed by Kohonen (1995) is employed in this work. SOM is one of the neural network model based on unsupervised and competitive learning. It provides a mapping with preserving topology from the high-dimensional space to two-dimensional plane, so called map. Although SOM does not remain the direction and distance in the original high-dimensional space, nearby points in the high-dimensional space are mapped to the nearby points on SOM. Roughly speaking, a relation between high-dimensional data and SOM is similar to the relation between the earth
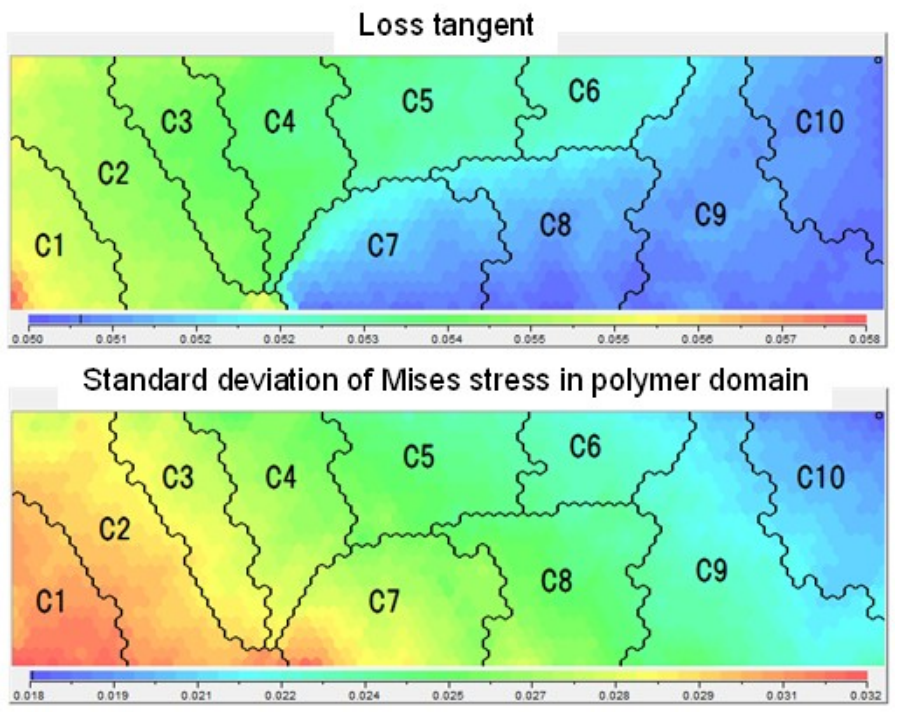

Radius of aggregate

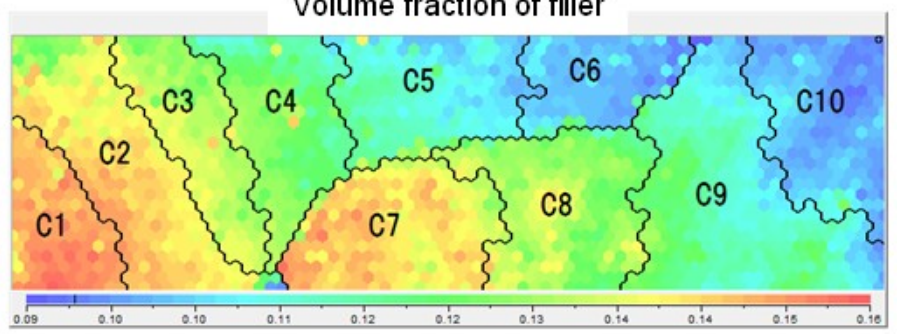

Volume fraction of bound rubber

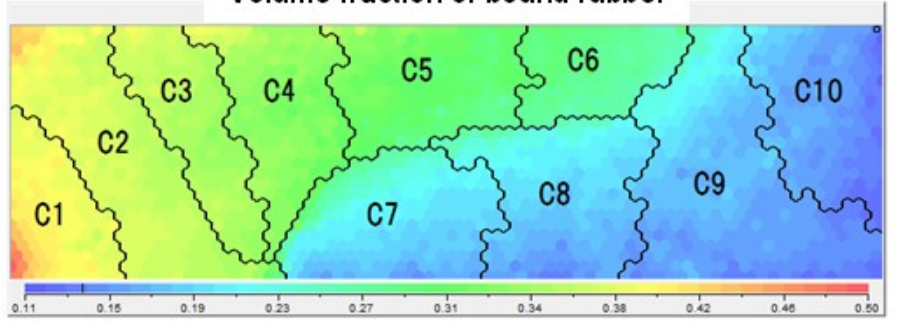

Figure 9. Contour plot of four objective functions, four design variables and two additional variables on the self-organizing map constructed using four objective functions. 
and a world map. Nearby countries on the earth are mapped to nearby positions on a world map. SOM is useful not only for visualization of high-dimensional data but also for the cluster analysis for design problems in industry (Koishi et al. 2006 \& Koishi et al. 2014).

Using NSGA-II, ten-dimensional data of about 4,000 models were obtained for data mining. Each data contains four objective functions and four design variables and two additional variables, volume fraction of polymer and that of bound rubber. Figure 9 shows the contour plot of four objective functions, four design variables and two additional variables on the same SOM generated using four-dimensional objective functions space.

Each map shown in Figure 9 is divided into ten clusters, C1-C10. The relation between each objective function can be understood visually by comparing upper four maps in this figure. It is shown that modulus (to be maximized) has a tradeoff with loss tangent (to be minimized). Cluster C10 is the best design domain on minimization of loss tangent. The desirable cluster to maximize modulus is C1. Furthermore, the figures show the correlation between average and standard deviation of Mises stress. According to visual data mining using Figure 9, we obtain the following results:

- The volume fraction of bound rubber, more than that of filler , greatly contributes to mechanical properties of filled rubbers,

- The radius of aggregate contributes to mechanical properties of filled rubbers.

\section{CONCLUSIONS}

For the morphological material design of filled rubbers, multi-objective design exploration based on multi-scale random model, FFT-based scheme, NSGA-II and self-organizing map was proposed in this work. The parametric models of morphology are generated using multi-scale random model. The FFTbased scheme has big advantage against FEM for large-scale viscoelastic simulation from the view points of time and memory size. For the MODE of filled rubbers, the computations of 4,000 large-scale models which consist of 134 million elements were carried out on TSUBAME, super computer at Tokyo Institute of Technology. As a result of data mining, the following conclusions are drawn. The volume fraction of bound rubber plays a major role in the material design of filled rubbers. Furthermore, the radius of aggregates contributes to mechanical properties of filled rubbers.

MODE for filled rubbers in which the rubber matrix is constituted of two distinct polymers will be studied in a next step.

\section{ACKNOWLEDGMENT}

This research used TSUBAME, supercomputer at Global Scientific Information and Computing Center in Tokyo Institute of Technology though the HPCI System Research Project (Project ID: hp160039).

\section{REFERENCES}

Akutagawa, K. \& Yamaguchi, K. \& Yamamoto, A. \& Heguri, H. \& Jinnai, H. \& Shinbori, Y., 2008, Mesoscopic Mechanical Analysis of Filled Elastomer with 3D-Finite Element Analysis and Transmission Electron Microtomography, Rubber Chemistry and Technology, 81, 2, 182-189.

Deb, K. \& Agrawal, S. \& Pratab, A. \& Meyarivan, T., 2000, A Fast Elitist Non-Dominated Sorting Genetic Algorithm for Multi-Objective Optimization: NSGA-II, KanGAL report 200001.

Figliuzzi, B. \& Jeulin, D. \& Faessel, M. \& Willot, F. \& Koishi, M. \& Kowatari, N., 2016, Modeling the Microstructure and the Viscoelastic Behaviour of Carbon Black Filled Rubber Materials from 3D Simulations, Technische Mechanik, 36, 1-2, 32-56.

Hagita, K \& Arai, T. \& Kishimoto, H. \& Umesaki, N. \& Shinohara, Y. \& Amemiya, Y., 2007, Two-Dimensional Pattern Reverse Monte Carlo Method for Modelling the Structures of Nano-Particles in Uniaxial Elongated Rubbers, Journal of Physics: Condensed Matter, 19, 33, 335317.

Hagita, K \& Arai, T. \& Kishimoto, H. \& Umesaki, N. \& Suno, H. \& Shinohara, Y. \& Amemiya, Y., 2008, Structural Change of Silica Particles in Elongated Rubber by Two-Dimensional Small-Angle X-Ray Scattering and Extended Reverse Monte Carlo Analysis, Rheologica Acta, 47, 537-541.

Jean, A. \& Willot, F. \& Cantournet, S. \& Forest, S. \& Jeulin, D., 2011, Large-Scale Computations of Effective Elastic Properties of Rubber with Carbon Black Fillers, International Journal for Multiscale Computational Engineering, 9, 3, 271-303.

Kadowaki, H. \& Hashimoto, G. \& Okuda, H. \& Higuchi, T. \& Jinnai, H. \& Seta, E. \& Saguchi, T., 2016, Evaluation of the Appropriate Size of the Finite Element Representative Volume for Filled Rubber Composite Analysis, Mechanical Engineering Journal, 3, 5, 16-00372.

Kohonen, T., 1995, Self-Organizing Map, Springer.

Koishi, M. \& Shiratori, M. \& Miyoshi, T. \& Kabe, K, 1997, Homogenization Method for Dynamic Viscoelastic Analysis of Composite Materials, JSME International Journal, Series $A, 40,3,306-312$.

Koishi, M. \& Shida, Z., 2006, Multi-Objective Design Problem of Tire Wear and Visualization of Its Pareto Solutions, Tire Science and Technology, 34, 3, 170-194.

Koishi, M. \& Miyajima, H. \& Kowatari, N., 2014, Conceptual Design of Tires using Multi-Objective Design Exploration, Proceedings of the Jointly Organized 11th World Congress on Computational Mechanics - WCCM XI, 5th European Congress on Computational Mechanics - ECCM V and 6th European Congress on Computational Fluid Dynamics ECFD VI, Barcelona, Spain, July 20-25, 3180-3189.

Willot, F., 2015. Fourier-based schemes for computing the mechanical response of composites with accurate local fields, Comptes Rendus Mecanique, 343, 3, 232-245. 